\title{
Aprendizagem Colaborativa Em Construção Coletiva Multimídia
}

\author{
Andréia Machado Oliveira \\ PGIE-UFRGS/NESTA-UFRGS/Colégio Marista Rosário \\ andreiao@cpovo.net \\ Adriana Justin Cerveira Kampff \\ PGIE-UFRGS/Colégio Marista Rosário \\ adriana@maristas.org.br \\ Roxane Leandra dos Santos Miranda \\ Colégio Marista Rosário \\ roxane@ maristas.org.br \\ Mafalda Roso \\ Colégio Marista Rosário \\ mafalda@maristas.org.br
}

\section{Resumo}

O presente trabalho apresenta livros multimídia construídos de modo colaborativo, cooperativo e hipermidiático. O projeto, envolvendo $5^{\mathrm{a}}, 6^{\mathrm{a}}$ e $7^{\mathrm{a}}$ séries do Ensino Fundamental, consistiu no desenvolvimento de três livros, cada um elaborado de forma colaborativa por todas as turmas de uma dada série, focando a percepção dos alunos sobre temas como liberdade, drogas, corrupção, relacionamentos, escolhas éticas ou não. Utilizouse a abordagem de uma metodologia hipermídia produzida a partir da hibridização das linguagens verbal, visual e sonora. Cada obra possui vários finais diferentes que revelam a percepção crítica e a postura de cada grupo diante de temas controversos, dos quais eles mesmos podem ser protagonistas.

Palavras-chave: aprendizagem colaborativa, multimídia, construção coletiva.

\section{Collaborative Learning In Multimedia Collective Production}

\section{Abstract}

This paper presents multimedia books produced in a collaborative, cooperative and hypermediatic way. The project involving the students attending 5th., 6th., and 7th. Grades of elementary school, included the development of three books, each of them cooperatively produced by all the groups of certain grade, focusing the students' perceptions on subjects such as freedom, drugs, corruption, relationships, ethic and non-ethic choices. A hypermediatic methodology produced from the hybridization of verbal, visual and sound languages was used. Each work has several different endings revealing each group's critical thinking and positioning on controversial topics, where the students themselves may be protagonists.

Keywords: collaborative learning, multimedia, collective production.

\section{Introdução}

O presente trabalho aborda a construção de livros multimídia coletivos a partir de seus procedimentos colaborativos, cooperativos e hipermidiáticos. Os livros elaborados oportunizam ao leitor uma postura ativa ao lê-los, pois são livros nos quais o leitor pode movimentar-se em sua leitura, a partir da escolha dos caminhos a seguir. O projeto, 
envolvendo $5^{\mathrm{a}}, 6^{\mathrm{a}}$ e $7^{\mathrm{a}}$ séries do Ensino Fundamental, consistiu no desenvolvimento de três livros, cada um elaborado de forma colaborativa por todas as turmas de uma dada série, focando temas transversais. O tema de cada livro surgiu a partir de discussões realizadas em todas as disciplinas de uma mesma série, envolvendo todos os alunos e professores da série. O texto do livro foi construído por todos os alunos de cada série na disciplina de Língua Portuguesa; e, a produção das imagens, diagramação e programação multimídia foram produzidas, no primeiro momento por todos os alunos para criação dos personagens e no segundo momento por alguns alunos da série que, voluntariamente, dispuseram-se a trabalhar extraclasse com a orientação das professoras de Educação Artística. Cada obra possui vários finais diferentes que revelam reflexão crítica e tomada de consciência de cada grupo diante temas controversos, dos quais eles mesmos podem ser protagonistas. A cooperação entre todos os alunos de uma mesma série propiciou a produção de textos mais criativos e imagens inéditas, uma vez que a construção dos livros ocorreu de modo coletivo desde a escolha do tema até o produto final. Ainda, ressalta-se, na construção dos livros, a possibilidade da abordagem de uma metodologia hipermídia produzida a partir da hibridização das linguagens verbal, visual e sonora.

\section{Motivação do Projeto}

Esse projeto nasceu do interesse de um grupo de educadores do ensino fundamental em vivenciar novas abordagens pedagógicas de modo colaborativo, compreendendo $\mathrm{o}$ conhecimento como um todo complexo (Morin, 2000). O que hoje, para muitos, já são jargões na área da Educação, em uma escola atualizada com o mundo contemporâneo renova-se, na medida em que se discutem, com seriedade e profundidade, questões relativas a: como propiciar o trabalho com projetos envolventes; como permitir interações significativas através de trabalhos em grupo; como promover situações colaborativas, cooperativas e produtivas; como abordar temas transversais; como criar condições para uma ação interdisciplinar; como levar os alunos a posicionarem-se de maneira ética-estética frente a diferentes questões sociais; como oportunizar uma apropriação adequada das novas tecnologias em prol da aprendizagem.

A escolha pela proposta de trabalho com projetos surge a partir da necessidade do grupo de professores de abordar o conhecimento de modo processual e interdisciplinar. Conforme Machado (1998), o desenvolvimento de projetos no espaço educacional traz consigo uma série de possibilidades pedagógicas relevantes, tais como: respeito à individualidade (ritmo, interesses e habilidades dos envolvidos são contemplados em trabalhos dessa ordem); simulação de situações (em um ambiente de desenvolvimento de projetos, é possível "criar" situações imaginárias, permitindo a visualização de conceitos e a vivência de situações diferenciadas); fornecer rico matéria aos alunos (em quantidade e qualidade, possibilitando pesquisa, aprofundamento, análise e depuração de idéias); proporcionar um ambiente que realmente possa estimular e, por conseqüência, motivar (envolver os alunos em seu processo de aprendizagem, de maneira que participem ativamente em todas as fases de aquisição de informações e construção do conhecimento); fornecer suporte durante todo o processo, através dos membros dos grupos e do professor mediador (desenvolvendo atividades apoiadas por um professor inovador e orientador, permitindo aos alunos ganhos significativos de aprendizagem).

Observa-se que as Tecnologias da Informação e da Comunicação, em especial, as que suportam multimídia, oferecem apoio adequado ao trabalho por projetos, por possibilitarem $\mathrm{o}$ atendimento dos aspectos descritos acima (Kampff, 2001). 
Estudiosos do tema mostram que escrita, leitura, visão, audição, criação e aprendizagem são capturadas por uma informática cada vez mais avançada. Nesse cenário, insere-se mais um desafio para a escola, ou seja, o de como incorporar ao seu trabalho, apoiado na oralidade e na escrita, novas formas de comunicar e conhecer. (PCNs 1996b)

Salienta-se, ainda, que conforme Perrenoud (2000), cabe a escola contribuir para criar uma cultura tecnológica de base, devendo o professor apropriar-se das tecnologias novas que vêm alterando, substancialmente, as formas de como as pessoas localizam e acionam informações para criar e solucionar problemas, bem como os distintos modos de vivenciarem aspectos espaço-temporais. Os estímulos aos quais a sociedade é exposta impulsionam uma mudança no papel da escola e, com isso, a necessidade de romper-se com velhos paradigmas educacionais, centrados em currículos fragmentados, em memorização e transmissão de informações. Hoje, busca-se o desenvolvimento da inteligência de forma coletiva a partir das vivências do grupo, das trocas de saberes e de reflexões críticas.

\begin{abstract}
Toda educação verdadeiramente comprometida com o exercício da cidadania precisa criar condições para o desenvolvimento da capacidade de uso eficaz da linguagem que satisfaça necessidades pessoais - que podem estar relacionadas às ações efetivas do cotidiano, à transmissão e busca de informação, ao exercício da reflexão. (PCNs 1996a).
\end{abstract}

Deste modo, priorizando uma construção coletiva, os professores de cada série discutiram com suas turmas a possibilidade de elaborarem um livro multimídia que abordasse um tema transversal (PCNs, 1996c), buscando definir o tema conjuntamente.

A discussão levou as turmas a aprofundarem seus conhecimentos sobre o tema enfocado e a criarem/simularem diversas situações de conflito, descritas em seus textos ficcionais.

Percebe-se, neste contexto, o desempenho de uma inteligência coletiva no sentido de uma educação colaborativa, já que a construção do livro dependia da participação e colaboração de todos os alunos de cada série, realizando-se uma autoria coletiva. Tal educação tem a horizontalidade do saber como prática pedagógica, possibilitando ações de cidadania na medida em que a produção do sujeito intervém na configuração do coletivo, recriando-o constantemente. Nesta prática pedagógica, torna-se visível que a colaboração de cada sujeito-aluno é imprescindível na produção do livro final.

A educação para a participação, para a cooperação e para o comprometimento com o coletivo vem a corporificar o conhecimento como rede, de maneira descentralizada e inventiva. No projeto referido, buscando desencadear ações que permitissem articular os diversos elementos apresentados acima, promoveu-se uma integração mais ampla entre alunos/alunos, alunos/professores e professores/professores, não apenas pelos alunos de uma determinada turma, mas por todos os alunos e professores de uma mesma série.

Outro aspecto importante na abordagem da construção do livro multimídia é o uso de diversas linguagens. Além da produção textual, o projeto propôs-se a trabalhar com outras linguagens, indo do desenho às composições multimídia, buscando explorar o senso estético e a sensibilidade dos alunos. Com vários alunos, portanto, com diferentes traços, cuidou-se para validar as diversas expressões artísticas apresentadas pelo grupo envolvido. Os desenhos produzidos (primeiramente à mão), as imagens da internet e do banco de imagens da escola foram trabalhados em cores e efeitos em softwares de edição gráfica. Na produção final do livro utilizou-se animação das imagens com o som, propiciando que a expressão das diversas características imagéticas e sonoras se transformassem em co-autoria. 
Portanto, ao longo do projeto, priorizou-se construir um conhecimento com linguagem híbrida de imagem, som e texto, visando-se um jogo intelectual e intuitivo sobre argumentos éticos e estéticos. De acordo com Sergio Bairon (2004), há atualmente possibilidades de uma metodologia hipermídia de pesquisa científica que ultrapassa a divisão: ciência (escrita e leitura) e a arte (imagem e som). Modos de compartilhar ambientes digitais dialógicos, não lineares, interativos reticulados (umcontexto imagético no qual habitarão as interações), compostos por subjetividades interconectadas. Visou-se investigar como produzir construções imagéticas nos encontros e desencontros das interpretações associativas, não se limitando a representações e clichês, mas imergindo nos sentidos repletos de significações. Nas imagens digitais habitam uma usina de signos que devem ser navegados e (re)significados.

A imagem digital surge como atualizações provisórias de um campo de possibilidades, deslocando a linearidade para uma rede de multiplicidades. A imagem tornando-se autorefente sem a conexão obrigatória com o objeto exterior. De acordo com Tania Fonseca, "podemos supor que as potências de imagens digitalizadas instauram um novo regime semiótico em que o referente é anulado remetendo as imagens a si próprias" (2005, p. 127). A imagem não está mais no que é visível, todavia na remixagem e na simulação. Esclarecese, entretanto, que a imagem digital também precisa ser trabalhada para superar a condição do clichê. Para André Parente, "de fato nós temos duas maneiras de pensar a imagem: a imagem como ilusão que deve ser submetida ao inteligível, que a domestica, a ensina a falar, e a imagem como puro sensível e ser de sensação que afirma o real como novo" (1993, p.30). Busca-se extrair imagens jamais $v u$ das imagens déjà $v u$ do mundo representação. Imagens que sendo digitalizadas se desprendem do objeto externo, tornandose meta-imagens de um universo plástico que se atualiza conforme o contexto exigido.

Afirma-se, aqui, a importância de práticas pedagógicas que se fundamentam sobre metodologias hipermídia que buscam visualizar configurações espaciais e temporais que subvertam estruturas lineares e dicotômicas através de formas de expressão construídas na multiplicidade (Oliveira, 2006). Com a combinação de textos, imagens, sons e efeitos de animação, a editoração final de cada livro foi realizada em um software de autoria multimídia, criando coletivamente um livro digital que oportuniza ao leitor interagir e fazer escolhas e reflexões. O programa utilizado na edição do livro, que possibilita a escolha de vários caminhos, foi o Everest, produzido no Brasil.

\section{Livros Coletivos}

A proposta de trabalho desencadeadora do projeto foi a elaboração de um livro multimídia coletivo por série, escrito de forma coletiva por todas as suas turmas.

Participaram do projeto as turmas de $5^{\mathrm{a}}, 6^{\mathrm{a}}$ e $7^{\mathrm{a}}$ série do Ensino Fundamental, envolvendo sete turmas por série, num total de vinte e uma turmas atuantes do projeto, com aproximadamente setecentos alunos. A cada turma, de acordo com a temática (tema transversal) escolhida pela série, coube o desenvolvimento de um capítulo, coerente com o conjunto da obra.

Para descrever a organização do projeto, apresenta-se, a seguir, uma diferenciação entre os momentos de concepção do texto, da organização e ilustração das cenas, e da montagem dos livros multimídias. 


\subsection{Elaboração do texto}

Os professores e alunos de cada série estabeleceram a temática a ser desenvolvida a partir de discussões reflexivas.

Em discussão com a primeira turma (N1), levantaram problemas sobre a temática abordada e como tais problemas apresentam-se e são vivenciados em situações reais pelas pessoas. A partir daí, destacaram-se elementos para que a primeira turma (N1) pudesse iniciar o livro (capítulo 1). Os professores, que iniciaram o processo, promoveram uma discussão ampla na turma, favorecendo a organização das idéias surgidas e definindo um grupo para elaborar a redação do capítulo em questão. Cabe destacar que, além de criar personagens, contextos e situações de conflito, os escritores deveriam finalizar o capítulo com uma grande questão (situação apresentada) que possibilitasse escolhas e encaminhamentos bem diferenciados.

As turmas posteriores ( $\mathrm{N} 2$ e $\mathrm{N} 3)$ realizaram a leitura do capítulo 1 e, partindo dele, escreveram dois segundos capítulos para o livro, um para cada caminho que poderia ser escolhido pelo leitor no final da leitura do capítulo 1, finalizando-os, novamente, com questões para escolha. As turmas N4 e N5 leram o capítulo 1 (escrito por N1) e o capítulo 2 (escrito por N2) e escreveram duas versões para o capítulo 3, possíveis de serem lidas conforme as escolhas do leitor no momento da interação com o livro. De forma análoga, as turmas N6 e N7 partiram dos capítulos escritos por N1 e N3.

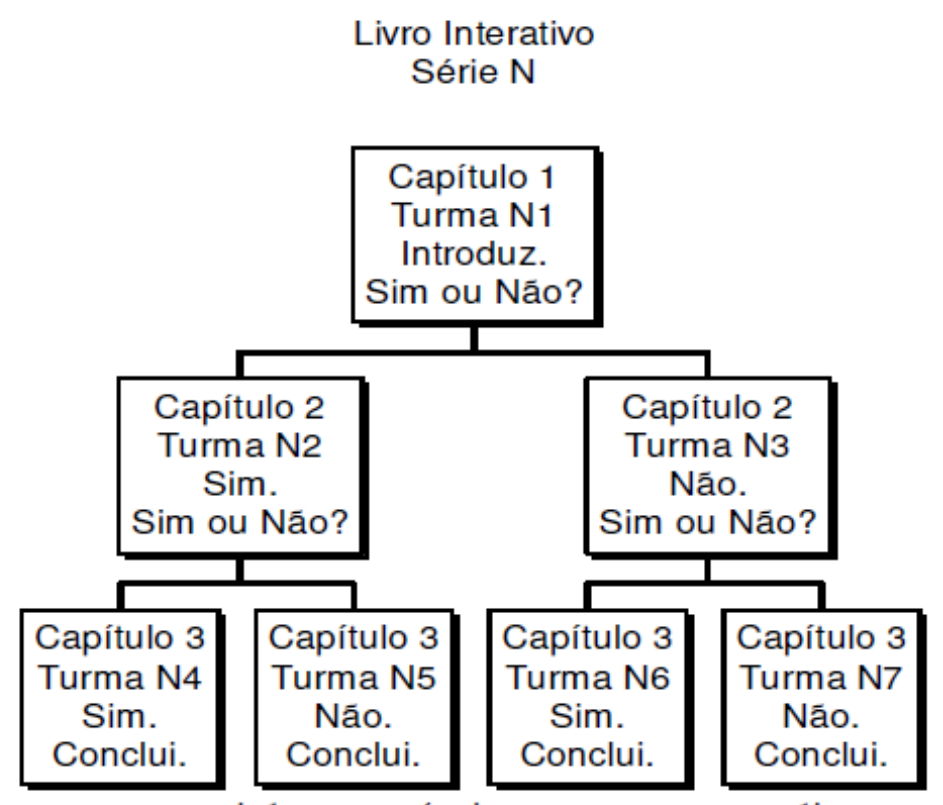

A Figura 1 representa os caminhos possíveis para percorrer o livro.

Figura 1 - Caminhos possíveis para a leitura do livro coletivo

De maneira bastante simplificada, apresenta-se, abaixo, um pequeno exemplo de encaminhamento para a construção dos capítulos, considerando como temática o uso de

drogas ilícitas: 
- Turma N1: Descrever, com riqueza de detalhes, o ambiente familiar e social de

um adolescente até o surgimento da possibilidade de experimentar drogas.

Questão: ele aceita? o Turma N2: Sim. Descrever as situações decorrentes. Num determinado momento, é oferecida ajuda para a sua recuperação. Questão: ele aceita?

_ Turma N4 Sim, se recupera. Tecer considerações futuras.

_ Turma N5: Não, continua com as drogas. Que fim terá? ○ Turma N3: Não. Descrever as conseqüências disso no seu grupo de amigos. Mantém a mesma postura no seu grupo?

_ Turma N6: Sim, acaba por envolver-se em outras situações indesejáveis. O que acontece?

_ Turma N7: Não, abandona o grupo ou promove situações para ajudá-los...

\subsection{Organização e ilustração das cenas}

Com o texto elaborado, foram realizados os trabalhos de roteirização das cenas e criação de ilustrações que comandaram todo o processo de criação. Até este momento todos os alunos da série participaram efetivamente do projeto. A partir de então foram organizadas oficinas extraclasse para discussão, escolhas, aproveitamento de imagens e criação final das ilustrações. Das vinte e uma turmas abarcadas, as oficinas contaram com, aproximadamente, sessenta alunos voluntários que trabalharam na produção do material gráfico. Sob a orientação constante dos professores da disciplina de Educação Artística o grupo desenvolveu o material gráfico utilizando os trabalhos do grande grupo (todos alunos da série), criando à partir deles e procurando novas formas e imagens. Nesta etapa os alunos utilizaram papel e lápis grafite. À medida que desenhavam, as imagens eram digitalizadas e trabalhadas com softwares para edição de imagem (Paint e PhotoShop). Como as imagens foram desenhadas por diversos alunos e, posteriormente, todos os desenhos eram manipulados no computador por todos os alunos envolvidos, as imagens se tornaram coletivas, incorporando ainda mais o sentido de coletivo que o projeto abrange. Cada imagem ilustrada à mão gerou ainda um novo conjunto de imagens com diversos tratamentos de cores, filtros e enquadramentos para a diagramação posterior (Figura 2).
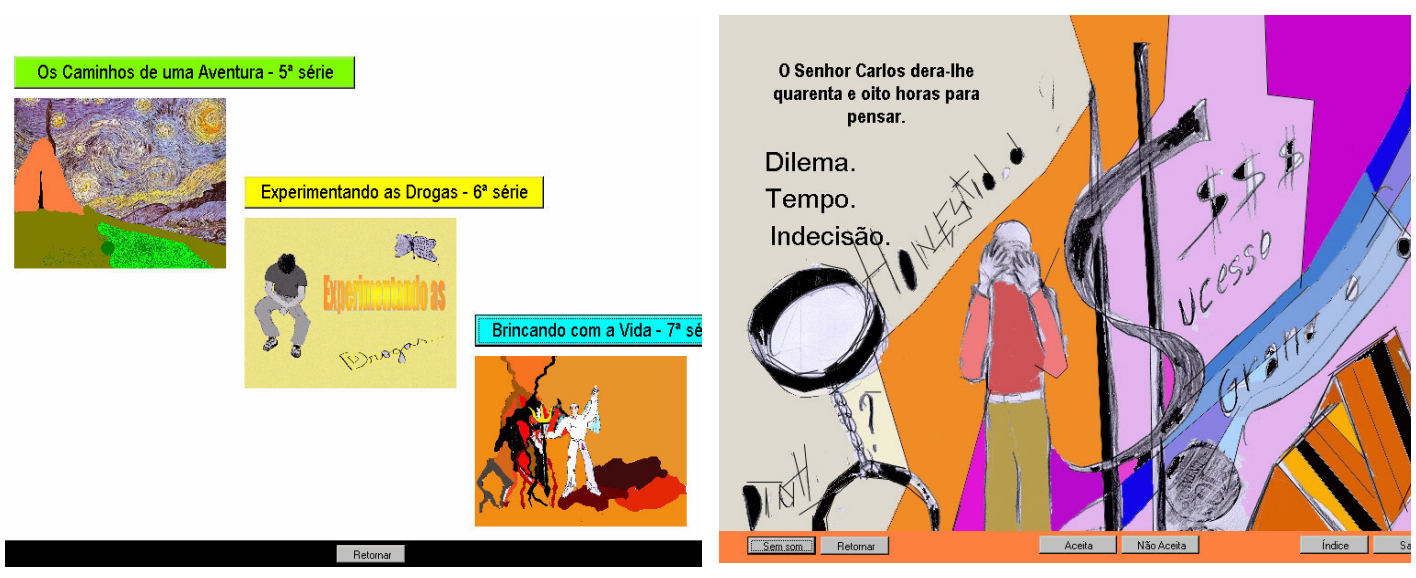
Figura 2 - Ilustrações dos livros coletivos

\subsection{Diagramação final: textos, imagens, animações e sons}

Com o material gráfico em produção, um grupo de alunos responsabilizou-se por organizar o livro multimídia, respeitando a roteirização, mas não se limitando a ela. Esse grupo, utilizando o software Everest (ferramenta de autoria multimídia), organizou cada cena, a partir de composições das imagens trabalhadas, incluindo novos elementos quando desejados, tais como sons e animações. Além disso, diagramaram o texto, buscando harmonizá-lo com a imagem final de cada cena. Para facilitar a navegação, incluíram e programaram botões para tocar e parar as músicas, para avançar e retroceder na história, para voltar ao menu principal e para fazer as escolhas em momentos decisivos.

\subsection{Produto Final}

Os livros multimídia foram gravados em CDRoms e distribuídos para os alunos que participaram do projeto. Também foram disponibilizados na Biblioteca da escola e expostos na Feira do Livro de Porto Alegre. Com uma boa repercussão na comunidade local, devido à abordagem de temas transversais e à qualidade do material produzido, pretende-se utilizálos nas aulas de "Educação para o Pensar", disciplina que leva os alunos a refletirem e posicionarem-se sobre temas diversos e em outras disciplinas como material didático.

\section{Considerações Finais}

Fazer da escola um espaço de aprendizagem prazerosa e comprometida com a realidade social: eis o grande desafio. Ao abordar temas transversais, com grupos que extravasam as paredes da sala de aula e que podem expressar-se por meio de diferentes linguagens, iniciase essa caminhada. Com trocas mais intensas, discutem-se situações de conflitos, criam-se simulações, permitem-se escolhas e visualizam-se possíveis implicações decorrentes dessas. O desenvolvimento desse projeto oportunizou reflexões e aprendizagens significativas, não apenas aos alunos envolvidos no projeto, mas a todos que interagiram com o produto multimídia gerado, sensibilizando-os, através de diferentes canais sensoriais, para os assuntos abordados.

Finalizando, salienta-se a importância das NTICs (Novas Tecnologias de Informação e Comunicação) como dispositivos para novas abordagens metodológicas.

Como Guattari coloca, "nenhum campo de opinião, de pensamento, de imagem, de afectos, de narratividade pode, daqui para frente, ter a pretensão de escapar à influência invasiva da 'assistência por computador', dos bancos de dados, da telemática, etc..." (1993, p.177). Os processo educativos têm seu engendramento a partir das diversas tecnologias embutidas nas instituições e que se expressam como equipamentos coletivos de conhecimento. As tecnologias digitais, como equipamentos coletivos de conhecimento, coloca alguns desafios: como ir além do estático para interativo; do automatismo para estética; do autor para autoria coletiva; do clichê para semiose ilimitada na criação signíca; da tendência à homogeneização universalizante (territorialidade) para tendência à heterogeneidade 
singularizante (desterritorialização) dos sujeitos. Questões que podem ser pensadas a partir de paradigmas ético-esteticos em abordagens transdisciplinares das relações entre homemmáquina, homem e meio. Um modo de Educação expandida no cotidiano das experiências vividas, imersa no social em processualidades coletivas fundadas em invenções baseadas na cooperação e colaboração.

\section{Agradecimentos}

Além das autoras, participaram do desenvolvimento do projeto a professora de Educação Artística das $5^{\text {a }}$ séries: Tânia Mattiello Rossetti e as professoras da Disciplina de Português: Clarice Pedroso Zanette, Denise Maria Bastos Barros, Helena Zanotelli, Inês Farias Pinheiro, Maria Filomena Trindade Winter, Nara Rangel Souto e Nívia Maria Hauschild Mondardo. Ainda, agradecemos aos alunos que participaram do projeto e à instituição Colégio Marista Rosário pelo constante apoio.

\section{Referências}

BAIRON, Sergio. Tendências da linguagem científica contemporânea em expressividade digital: uma problematização. Informática na Educação: Teoria \& Prática - Revista do PGIE da UFRGS. V.07-2, 2004.

FONSECA, Tania Galli. Poéticas do Virtual e os Processos de subjetivação. Informática na Educação: Teoria \& Prática - Revista do PGIE da UFRGS. V.08-1, 2005.

GUATTARI, Félix. Da produção de subjetividade. In: PARENTE, André (org) . Imagem Máquina. Rio de Janeiro: Ed.34, 1993.

KAMPFF, Adriana J. C; DIAS, Márcia Cantelli. Construção do Conhecimento em Ambientes de Pesquisa e Autoria Multimídia. Caderno Marista de Educação. V.1 N.1. Porto Alegre: Editora CMC, 2001.

MACHADO, Nilbo. Interdisciplinaridade Aplicada. São Paulo: Ed. Érica, 1998.

MORIN, Edgar. Os sete saberes necessários à educação do futuro. Brasília, DF: Ed. Cortez e UNESCO, 2000.

OLIVEIRA, Andréia Machado; FONSECA, Tania Galli. Conversas entre Escher e Deleuze: tecendo percursos para se pensar a subjetivação. Revista Psicologia e Sociedade. Vol.18, $\mathrm{n}^{\circ}$ 3, set/dez, 2006.

PARENTE, André. O virtual e o hipertextual. Rio de Janeiro: Pazulin, 1999.

Parâmetros Curriculares Nacionais - Ensino Fundamental - Língua Portuguesa (1996a) http://www.bibvirt.futuro.usp.br/textos/humanas/educacao/pens/fundamental/portugues. html

Parâmetros Curriculares Nacionais - Ensino Fundamental - Matemática (1996b) http://www.bibvirt.futuro.usp.br/textos/humanas/educacao/pcns/fundamental/matematic a.html\#2.3.1.3. 
Parâmetros Curriculares Nacionais - Ensino Fundamental- Temas Transversais (1996c) http://www.bibvirt.futuro.usp.br/textos/humanas/educacao/pcns/fundamental/transversai s.html

PERRENOUD, Philippe. Dez novas competências para ensinar. Porto Alegre: Artes Médicas Sul, 2000. 